\title{
Immunological Evaluation of the Intestinal Mucosa of Broiler Chicks Treated with Lactobacillus Spp. and Challenged with Salmonella Enteritidis
}

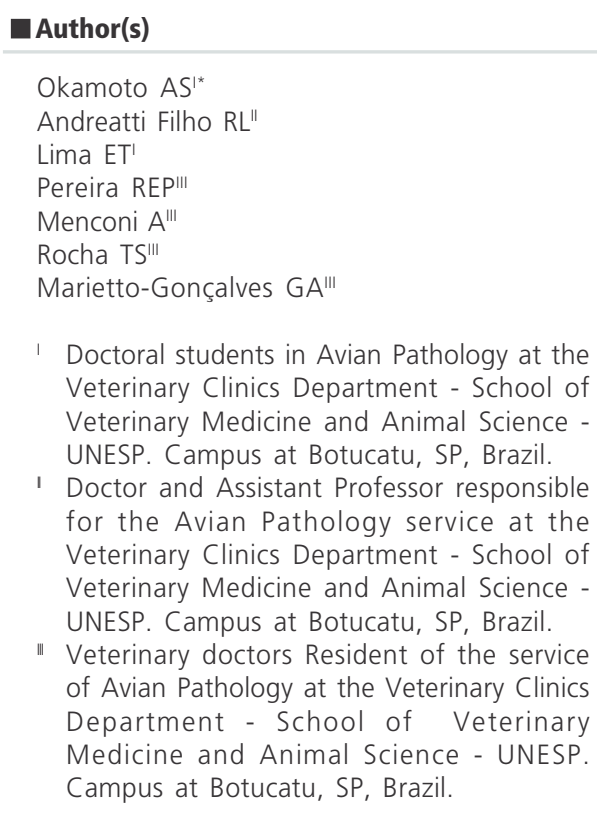

\section{Mail Address}

Adriano Sakai Okamoto

Av. Vital Brasil, $630 \mathrm{~A}$

Vila São Lúcio

18.603-193. Botucatu, SP, Brasil

Tel: (014) 9786.3057

E-mail: sakai@fmvz.unesp.br

Keywords

Chicks, IgA, Lactobacillus, Salmonella.

\section{Acknowledgments}

We are grateful for the financial support of FAPESP and for the constant incentive for research.

\section{ABSTRACT}

This study aimed at the antibody production by intestinal mucosa of broilers chicks were orally inoculated with Lactobacillus spp. at one and/or 21 days of age, and subsequently challenged with Salmonella enterica, subspecies enterica, serotype Enteritidis ( $S$. Enteritidis). A total number of 288 drug-free broiler chicks was divided into 6 groups (groups A, B, C, D, E, and F), according to age at Lactobacillus spp. inoculation and SE challenge. The intestinal mucosa immune response was determined as the production of immunoglobulin A against $S$. Enteritidis, and evaluated by the EnzymeLinked Immunosorbent Assay (ELISA) technique in intestinal washing fluid. Groups treated with Lactobacillus spp. presented higher IgA production only when the chicks were challenged with $S$. Enteritidis at 21 days of age. Nevertheless, the expected stimulus for intestinal mucosa antibody production induced by Lactobacillus spp was observed in only some of the treated groups, demonstrating that the protocol utilized in the present experiment resulted in few beneficial effects for chicks, particularly during the first days of life.

\section{INTRODUCTION}

Probiotic organisms have been suggested as an useful tool for the prevention of some infectious diseases in chickens, such as salmonellosis (Nagy et al., 1979).

Several studies demonstrate higher production of IgA against microorganisms after treatment with probiotic strains (Arechederra \& Cayon, 2000). Perdigón et al. (1991) also showed that the protective effect of Lactobacillus casei against Salmonella Typhimurium and Escherichia coli was associated mainly with the high level of IgA antipathogen antibodies present in intestinal secretions. Lactobacillus casei plays an important role in the prevention of enteric infections, and a low dose provides protection against intestinal infections by increasing IgA secretion into the intestinal lumen, thus providing adequate defenses for the mucosal surface. $\lg \mathrm{A}$ is the predominant class of immunoglobulins found in intestinal, pulmonary, urogenital, tear, salivary and nasal mucus secretions (Lopes Filho \& Migaça, 1994; Noronha, 1995; Elia \& Souza, 2002).

The present study aimed at evaluating the production of secretory immunoglobulin $A$ in the intestinal lumen of chicks treated with Lactobacillus spp. and subsequently challenged with Salmonella Enteritidis.

\section{MATERIAL AND METHODS}

Two hundred and eighty-eight day-old broiler chicks, non-sexed, were divided into six groups of 48 chicks each (Table 1). Each experimental 
Okamoto AS, Andreatti Filho RL, Lima ET, Pereira REP, Menconi A, Rocha TS, Marietto-Gonçalves GA
Immunological Evaluation of the Intestinal Mucosa of Broiler Chicks Treated with Lactobacillus Spp. and Challenged with Salmonella Enteritidis group was housed in isolation in heated wire cages, receiving water and non-medicated feed ad libitum. Chicks were negative for Salmonella spp. as determined by bacteriological examination of 8 chicks upper animal, per experimental group (EWING, 1986).

The strains Lactobacillus acidophilus, L. fermentum, $L$. reuteri and $L$. salivarius were isolated from the crop and the ceca of broiler breeders in lay, and were cultured under anaerobiosis in DeMan-Rugosa-Sharpe culture medium (MRS - Oxoide, Hampshire, United Kingdom), specific for Lactobacillus sp. The strains were identified using Gram staining method, and potassium hydroxide, catalase production, production of gas from glucose, and the test of fermentation of carbohydrates API $50 \mathrm{CH}^{\circledR}$ tests. All Lactobacillus spp. strains were separately cultivated in tubes containing MRS broth at $37^{\circ} \mathrm{C}$ for 48 hours in anaerobiosis. One $\mathrm{mL}$ of each culture was removed and mixed with $1 \mathrm{~mL}$ of the other cultured strains, composing the inoculum, which contained $2.0 \times 10^{9}$ colony forming units (CFU)/mL.

Salmonella enterica, subspecies enterica, serotype Enteritidis (SE) phagotype 4 was used as challenged strain. It was isolated from the liver of broiler breeders. This strain is a mutant resistant to nalidixic acid (Nal) and rifampicin (Rif), developed through successive cultures in brilliant green agar (BGA-OXOIDHampshire, UK) containing nalidixic acid $(100 \mu \mathrm{g} / \mathrm{mL}$ of medium) and rifampicin (100 $\mathrm{g} / \mathrm{mL}$ of medium), according to Andreatti Filho et al. (1997), to allow bacterial enumeration.

In all the experiments, the inocula consisted of SE cultivated in brain-heart broth (BHI-OXOID- Hampshire, United Kingdom) incubated at $40^{\circ} \mathrm{C}$ for 12 hours, and diluted 100 times also in $\mathrm{BHI}$ at the time of use. The inocula contained $3.0 \times 10^{8} \mathrm{CFU} / \mathrm{mL}$ and $3.3 \times 10^{7} \mathrm{CFU} /$ $\mathrm{mL}$ in the first and second challenge, respectively. The inocula were directly placed in the esophagus with the aid of a $1-\mathrm{mL}$ graduated pipette at $0.5 \mathrm{~mL} / \mathrm{chick}$.

At 14, 21, 28, and 35 days of age, eight chicks from each group were euthanized by cervical dislocation, aseptically necropsied, and the intestine was removed from the proximal portion of the duodenum up to the distal portion of the rectum.

Two $\mathrm{mL}$ of buffer solution (PBS containing $0.02 \%$ sodium azide, $1 \%$ bovine serum albumin, $1 \mathrm{mM}$ phenylmethyl sulfonyl fluoride (PMSF), and $5 \mathrm{mM}$ ethylene diamine tetra-acetic acid (EDTA) disodium salt (SIGMA Aldrich ${ }^{\circledR}$ ) were infused with the aid of a disposable sterile syringe in the proximal portion of the duodenum and collected in the distal portion of the rectum. The intestinal fluid was centrifuged at 1200x $\mathrm{g}$ for 15 minutes, and the supernatant was submitted to indirect Enzyme Linked Immunosorbent Assay test (ELISA).

In order to evaluate the immune response by indirect ELISA, the SE antigen was prepared by sonication of bacteria cultivated in $\mathrm{BHI}$ and purified by centrifugation of the suspension (HASSAN, 1990). Sterile polyethylene plates containing 96 wells (Hexxis ${ }^{\circledR}$ ) were filled with $50 \mu \mathrm{L}$ antigen at 1:50 dilution with carbonatebicarbonate buffer $\left(15 \mathrm{mM} \mathrm{Na} \mathrm{CO}_{3}, 35 \mathrm{mM} \mathrm{NaHCO}\right.$, SIGMA Aldrich ${ }^{\circledR}$ ) at $\mathrm{pH}$ 9.6, and incubated at $4^{\circ} \mathrm{C}$ for 18 hours. After each step, reagents were removed, and the wells rinsed four times with PBS added to $0.01 \%$ TWEEN 20 (PBST). Plates were stopped with increases of $100 \mu \mathrm{L}$ carbonate-bicarbonate buffer solution with $2 \%$ bovine serum albumin (BSA-Sigma Aldrich $\left.{ }^{\circledR}\right)$, and incubated for 60 minutes at $37^{\circ} \mathrm{C}$ to prevent interference in the reaction. Then, $50 \mu \mathrm{L}$ of each sample of fluids from intestinal rinsing, previously diluted in PBST + BSA 0.5\% (1:2), were placed in each well, and the plates were incubated at $37^{\circ} \mathrm{C}$ for 60 minutes. Plates were rinsed again, and $50 \mu \mathrm{L}$ conjugate (sheep antibody anti-lgA of hen linked to peroxidase SIGMA $\left.{ }^{\circledR}\right)$ diluted in PBST + BSA 0.5\% (1:40000) were added, with new incubation at $37^{\circ} \mathrm{C}$ for 60 minutes. After new rinsing, substrate containing $3 \mu \mathrm{L}$ hydrogen peroxide at 30\%, 100 $\mathrm{L}$ tetramethylbenzadine (TMB) at $10 \mathrm{mg} / \mathrm{mL}$ (diluted in Dimethyl Sulfoxide-DMSO) and $10 \mathrm{~mL}$ acetate / citrate buffer $0.1 \mathrm{~mol} / \mathrm{L}$, pH 6.0, were

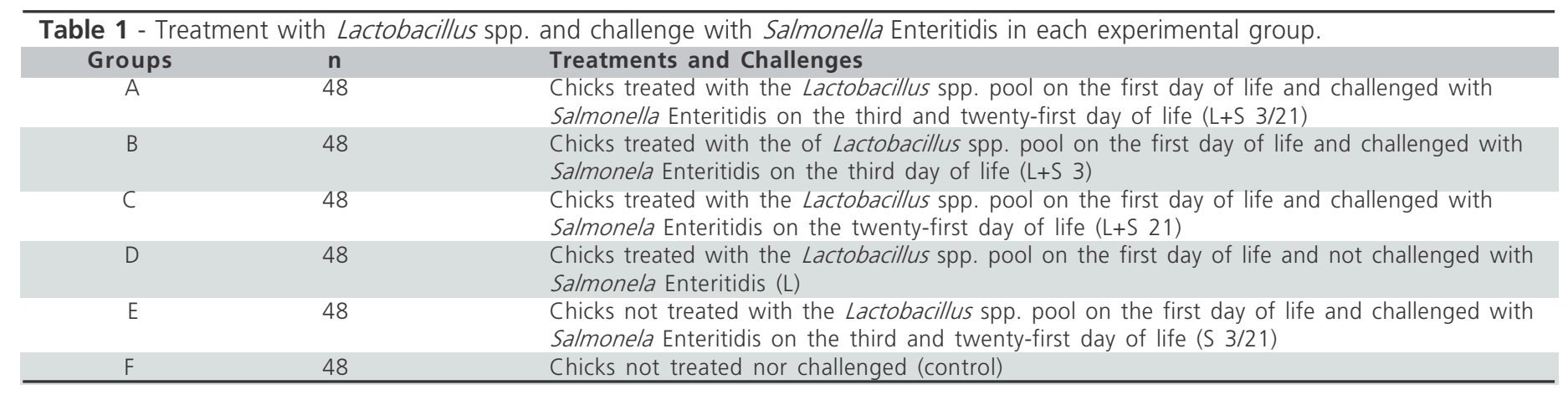


Okamoto AS, Andreatti Filho RL, Lima ET, Pereira REP, Menconi A, Rocha TS, Marietto-Gonçalves GA
Immunological Evaluation of the Intestinal Mucosa of Broiler Chicks Treated with Lactobacillus Spp. and Challenged with Salmonella Enteritidis added, comprising a total volume of $100 \mu \mathrm{L} /$ well. Plates remained for 15 minutes at $28^{\circ} \mathrm{C}$ in the absence of light. Finally, $50 \mu \mathrm{L}$ hydrochloric acid $(\mathrm{HCl}) 2 \mathrm{~N}$ were added to each well to stop the reaction. Measurements were carried out using an ELISA plate reader at wavelength of $450 \mathrm{~nm}$.

Kruskal-Wallis non-parametric test was utilized to compare ELISA index means among treatments and time. Groups were compared at each time using analysis of variance in a completely randomized experimental design, with eight replicates per treatment (ZAR, 1996).

\section{RESULTS AND DISCUSSION}

One of the main sources of Salmonella transmission to humans are poultry products (Gast, 1997). The present work used Salmonella Enteritidis due to its increasing participation in cases of foodborne infection (Fernandes, 1995) and because phagotype 4 is one of the most pathogenic and prevalent strains (Doherty, 1997). The infective dose of Salmonella spp. experimentally used in day-old chicks varies in literature between $10^{2}$ and $10^{8} \mathrm{CFU} / \mathrm{bird}$ (SNOEYENBOS et al., 1985). The experimental reproduction of Salmonella Enteritidis infection in day-old chicks, in the present experiment used intraesophageal inoculation. The infective dose used varying from $10^{7}$ to $10^{8} \mathrm{CFU} / \mathrm{bird}$, resulted in a high number of infected birds, and significant cecal colonization in the groups challenged at 14 days of age. We decided to use the oral route (intraesophageal inoculation) in order to ensurethat each bird would receive the recommended dose.

The oral administration of Lactobacillus cultures to day-old chicks apparently did not interfere with the response of intestinal IgA production after subsequent challenge with SE.

The results of the detection of specific IgA against SE (Table 2) obtained by ELISA in optical density (OD) were converted into ELISA coefficient in order to eliminate possible OD variation due to changes in environmental temperature during the test, leading to a better interpretation of the results. This coefficient was obtained by subtracting the sample mean (OD) from the negative control mean (OD), divided by the positive control mean (OD) minus the negative control mean (OD) (IDEXX®).

In group A, IgA significantly increased until 28 days, with subsequent decrease at 35 days of age. In the group $B, \lg A$ increased with bird age up to 28 days, and decreased at 35 days of age. However, in group
C, IgA levels remained constant until challenge at 21 days of age, when a significant increase was observed until the end of the experiment. In group $D$, there was no significant difference among the analyzed times, probably due to the absence of stimulus by $S$. Enteritidis. In Group E, IgA increased up to 21 days, followed by a decreased at 35 days de age. In group $F$ (negative control), IgA remained constant at the different ages, showing that, without the stimulus SE challenge, the production of specific IgA against SE does not occur.

\section{ELISA Coefficient $=$ (Sample Mean - Negative Mean) / (Positive Mean - Negative Mean)}

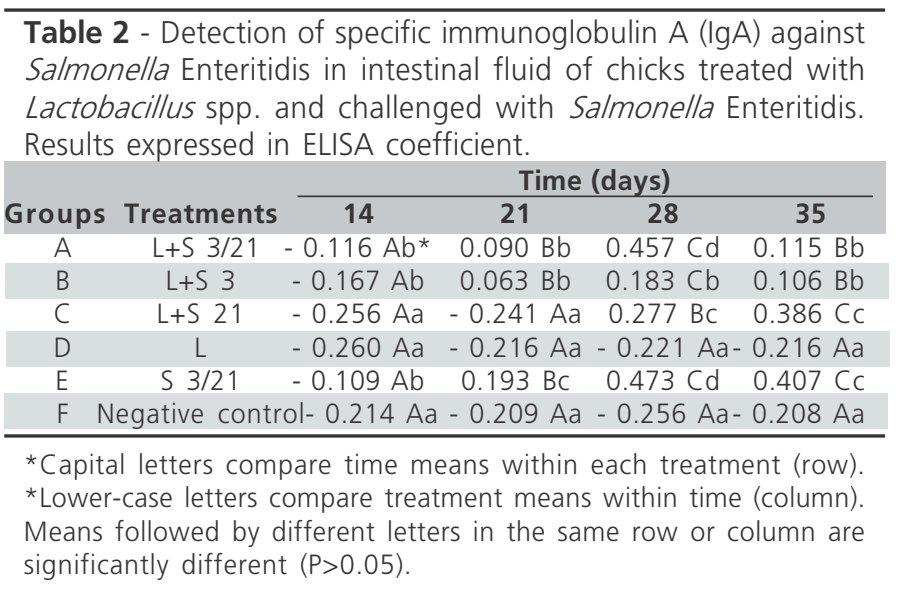

At 14 days of age, the results of the groups challenged with SE at three days of age (groups A, B, and $E$ ) werevery similar, and higher than the other groups, which were not challenged at three days of age. When birds reached 21 days of age, similar results were be observed, except for group $E$, which IgA indices were higher than to those of the other groups.

At the third and forth collection (28 and 35 days), groups $D$ and $F$ were not significantly different, presenting the lowest $\lg A$ indices, probably due to the absence of stimulus (challenge).

At the third collection (28 days), group B still presented higher indeces than those of groups $D$ and $F$, followed by group $C$, which was followed only by groups $A$ and $E$, which presented the highest indices at that time. At the final collection ( 35 days), groups A and B were similar to each other, as were groups $C$ and $E$, which presented the highest $\lg \mathrm{A}$ indices of the experiment.

Groups A and E presented higher IgA production (Table 2) as compared to the other groups after the second challenge (21 days), demonstrating that a 
higher number of results in stronger stimulus of the immune system, and, as verified by Nagy et al. (1979) and Wold and Hanson (1994), this stimulus increases the production of $\lg \mathrm{A}$. At the end of the experiment (35 days), the groups presenting high IgA production were group C, which was treated with Lactobacillus and received the second challenge on the $21^{\text {st }}$ day, and group $E$, which was submitted two challenges, thus being more stimulated to produce IgA.

It seems that $\lg \mathrm{A}$ response is dose- and agedependent, due to two challenges with SE (groups A and $E$ ), and challenge at 21 days of age (group C) stimulated higher IgA production than a single challenge at 3 days of age (group B).

Although all groups challenged with SE responded with an increase in intestinal $\lg A$ production, the treatment with Lactobacillus spp. before challenging the chicks with $S$. Enteritidis did not significantly increase IgA production. This is consistent with the study of Snoeyenbos et al. (1985), who observed that the colonization of the intestine with normal intestinal microbiota prior to challenge effectively limits, but does not totally prevent, infection by Salmonella spp. when challenge is higher than $10^{6} \mathrm{CFU} / \mathrm{chick}$

The beneficial effects of Lactobacillus spp. used probiotic to face bacterial colonization were already shown by several authors (Gusils et al., 1999; Maassen et al., 2000; Schiffrin, 1999), but in the present experiment, little beneficial action was observed in some groups. Several variables in the experimental protocols employed, such as time of culture, number of passages in culture medium, species of bacteria utilized, route of administration, of Salmonella serotype, infective dose, etc., may have contributed to the obtained results.

\section{CONCLUSIONS}

The expected stimulus for antibody production in the intestinal mucosa induced by Lactobacillus spp before challenge with SE was observed in the present experiment, but not in all treated groups, demonstrating that this type of treatment has few beneficial effects for chicks, particularly during the first days of life.

\section{REFERENCES}

Andreatti Filho RL, Silva EM, Curi PR. Ácidos orgânicos e microbiota cecal anaeróbia no controle da infection experimental de frangos por SalmonellaTyphimurium e Salmonella Enteritidis. Arquivo Brasileiro de Medicina Veterinária e Zootecnia 1997; 49:661-672.
Arechederra TM, Cayón D. Probióticos, algo mas que bacteria. uma era funcional. Revista Enfasis Argentina 2000; 6(5). [acesso em: 03 jun. 2002]. Disponível em: http://www.enfasis.com/ar alim/2000 05/NOTA.html

Doherty L. et al. An outbreak of Salmonella enteritidis phage type 4 in a rural community in Norther Ireland. Communicable Disease Report Review 1997; 7:73-76.

Elia C, Souza H. Imunologia da intestinal mucosa. [acesso em: 04 jun. 2002]. Disponível em: http://orbita.starmedia.com/ dia-adiagastro/entrevistas_base.html.

Ewing WH. Edwards and Ewing's: identification of enterobacteriaceae. $4^{\text {th }}$ ed. New York: Elsevier Science; 1986. p.181-245.

Fernandes SA. et al. Salmonella enteritidis: atual serotype no estado de São Paulo e susceptibilidade aos agentes antimicrobianos. Anais do $18^{\circ}$ Congresso Brasileiro de Microbiologia; 1995; Santos. p.103.

Gast RK. Paratyphoid Infections. In: Calnek BW, editor. Diseases of poultry. 10 $10^{\text {th }}$ ed. Ames: lowa State University Press; 1997. p.81-121.

Gusils C, Gonzalez SN, Oliver G. Some probiotic properties of chicken Lactobacilli. Canadian Journal of Microbiology 1999; 45: 981-987.

Hassan JO et al. Detection of Salmonella typhimurium infection of chickens by indirect ELISA. Veterinary Record 1990; 126:519-522.

Lopes Filho O, Migaça I. Imunologia do anel linfático de Waldeyer. In: Lopes Filho O, Campos CAH. Treated de otorrinolaringologia. São Paulo: Roca; 1994. p. 148-162.

Maassen CBM. et al. Strain-dependent induction of cytokine profiles in the gut by orally administered Lactobacillus strains. Vaccine 2000; 18:2613-2623.

Nagy IK, Bogal BS, Mackenzie T. Duration of anti-adhesive and bactericidal activities of milk from vaccinated sows on Escherichia coli 0149 in the digestive tract of piglets during the nursing period. Research in Veterinary Science 1979; 27:289-296.

Noronha IL. et al. Nefropatia mesangial primária de IgA : aspectos clínicos e imunopatológicos. Jornal Brasileiro de Nefrologia 1995; 17(1):21-29.

Perdigón G, Alvarez S, Pesce De Ruiz Holgado A. Immunoadjuvant activity of oral bactobacillus casei. influence of dose on the secretory immune response and protective capacity in intestinal infections. Journal of Dairy Research 1991; 58(4):485-496.

Schiffrin E. Los probioticos en la alimentación infantil. Reunión Sobre Probióticos; 1999; Madrid. Madrid.

Snoeyenbos GH. et al. Large-scale trials to study competitive exclusion of Salmonella in chickens. Avian Diseases 1985; 29:1004-1011.

Wold A, Hanson LA. Defense factors in human milk. Current Opinion in Gastroenterology 1994; 10:652-658.

Zar JH. Biostatistical analysis. New Jersey: Prentice Hall; 1996. 